\title{
BASAL FIRE SCARS AND THE OCCURRENCE OF DECAY IN LODGEPOLE PINE ${ }^{1}$
}

\author{
By V. J. NORDIN ${ }^{2}$
}

\section{$A B S T R A C T$}

An examination of lodgepole pines with basal fire scars has shown a correlation between the incidence of fungi entering the scars and the area of the scars. A number of fungi entering the scars and associated with red stain, other decays, and blue stain, are identified and illustrated. The significance of fire scars in the management of lodgepole pine in Alberta is discussed.

\section{INTRODUCTION}

The characteristics and implications of fire scars on eastern hardwoods and their relation to decay have been examined by Lachmund (8), McCarthy (9), Nelson et al (10), Hepting (5), and Hepting and Hedgecock (7). Hepting (6) has described procedures for the prediction of cull following fire in Appalachian oaks, and Gustafson (3) has correlated open basal fire wounds with the amount of decay present in standing timber in the Kentucky Highlands. In eastern Kentucky hardwoods, Gustafson (4) determined that the volume of decay developing from fire wounds amounted to $31 \%$ of the gross volume in trees of saw timber size. Recently, Toole and Furnival (12) have provided further data on the progress of decay in fire-scarred red oaks.

There is, however, a lack of similar information for trees in western North America. In Alberta, little is known regarding the distribution and disease implications of fire scars in lodgepole pine stands, except that the condition is sporadic throughout the range of the species and that up to $100 \%$ of the trees in local areas may have basal fire wounds. To contribute further data on this subject, the present paper summarizes the information collected during investigations of red stain in 85-year-old lodgepole pine stands located at Nordegg, Strachan, and Water Valley.

\section{Location of Studies}

Table I summarizes the location of plots and the numbers of trees sampled. Of five 1/10th-acre plots established in stands injured by ground fires, two were located in the vicinity of Strachan (Fig. 1, A), two near Nordegg (Fig. 1, B), and one in the area of Water Valley (Fig. 1, C).

\section{METHODS}

In each sample plot, the lodgepole pines were cut at a stump height of

${ }^{1}$ Manuscript received September 26, 1957. Contribution No. 421 from the Forest Biology Division, Science Service, Department of Agriculture, Ottawa, Canada.

${ }^{2}$ Associate Chief (Forest Pathology), Forest Biology Division, Ottawa, Canada. 


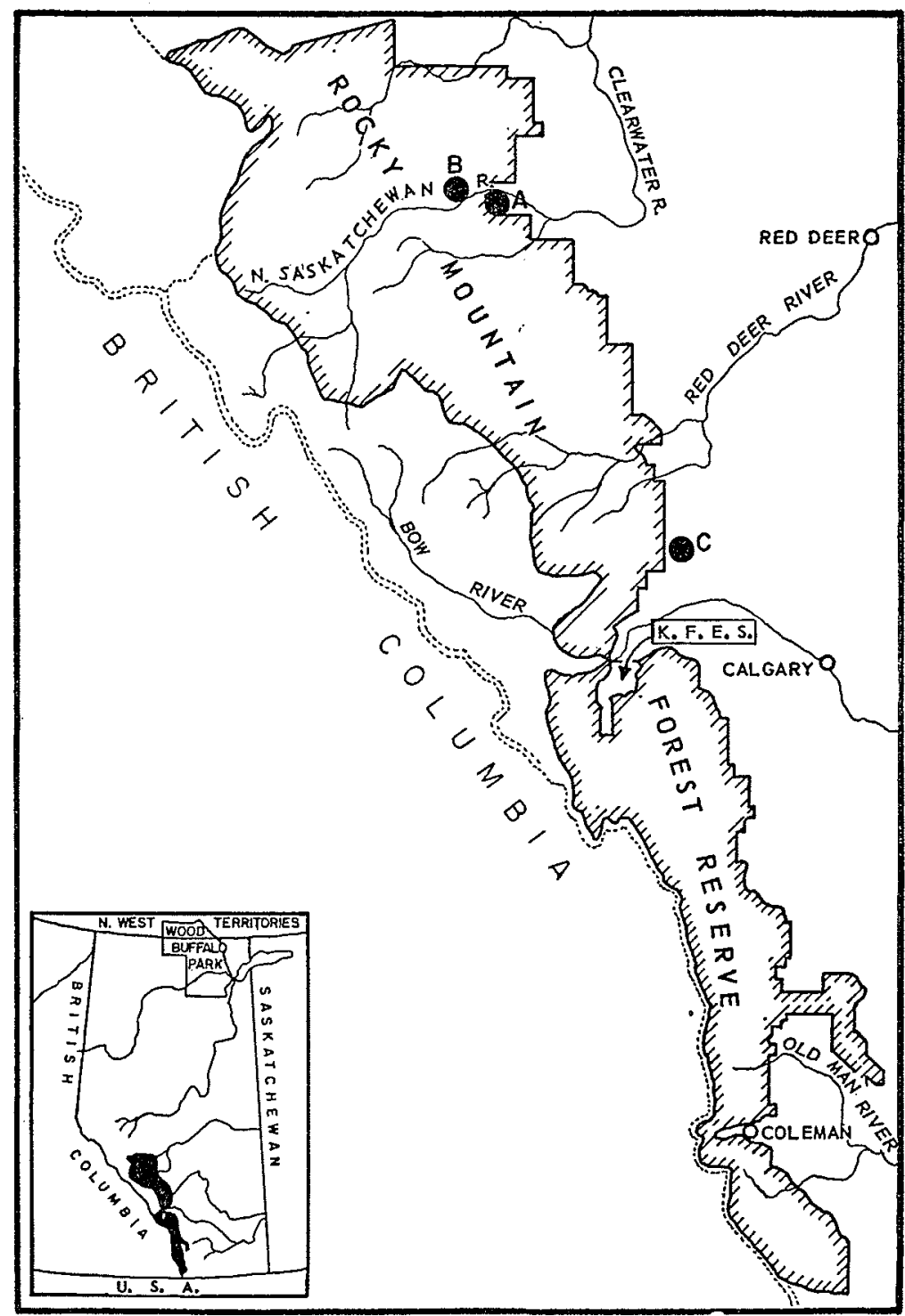

FIGURE 1

Outline map of part of Alberta showing the locations of areas studied. A, Section 7 , Township 38, Range 8, West of the Fifth Meridian, near Strachan; B, Section 10, Township 41, Range 14, West of the Fifth Meridian, near Nordegg; and C, Section 6, Township 29, Range 5, West of the Fifth Meridian, near Water Valley. 


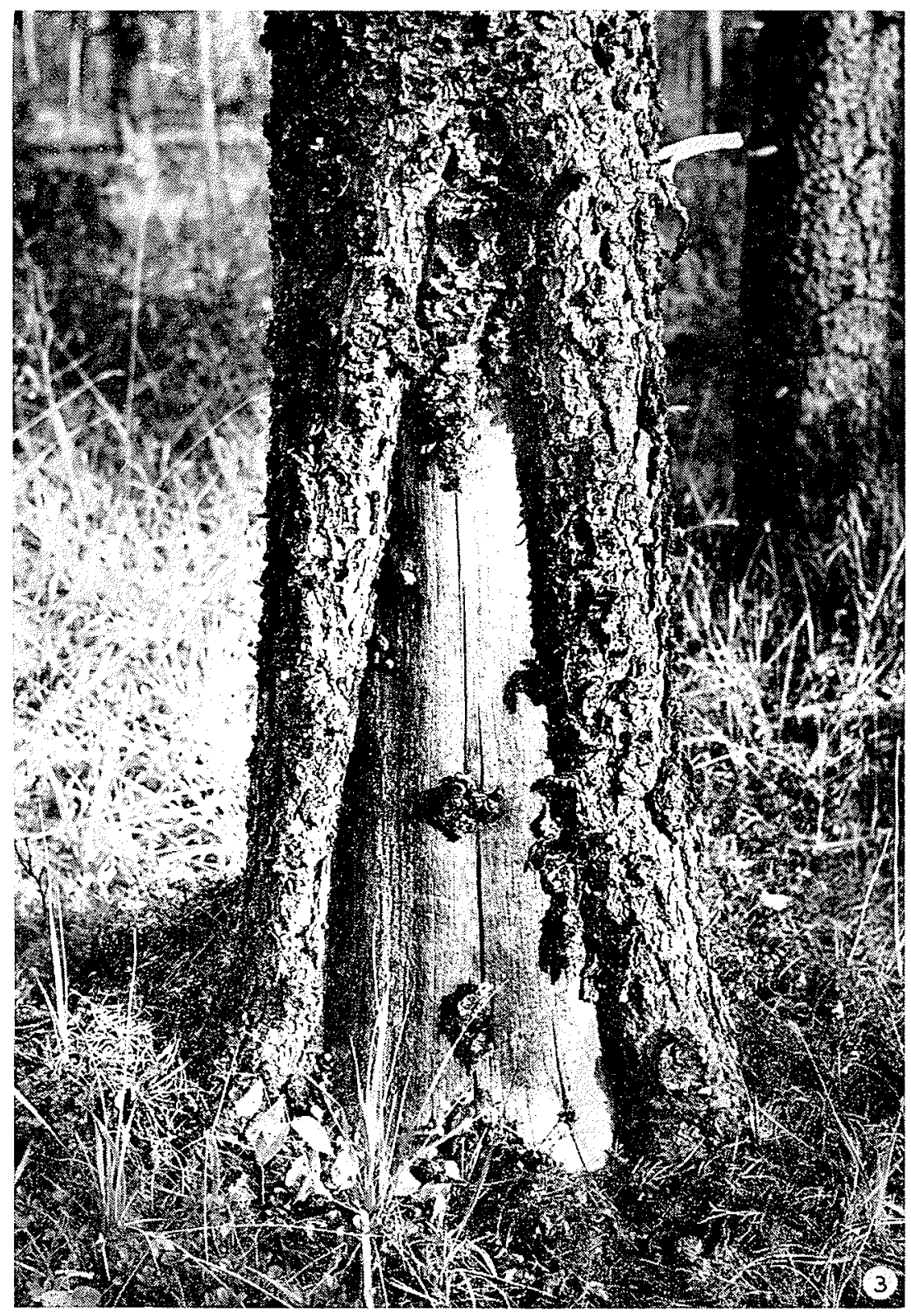

FIGURE 3

A typical basal fire scar, 33 years old. 


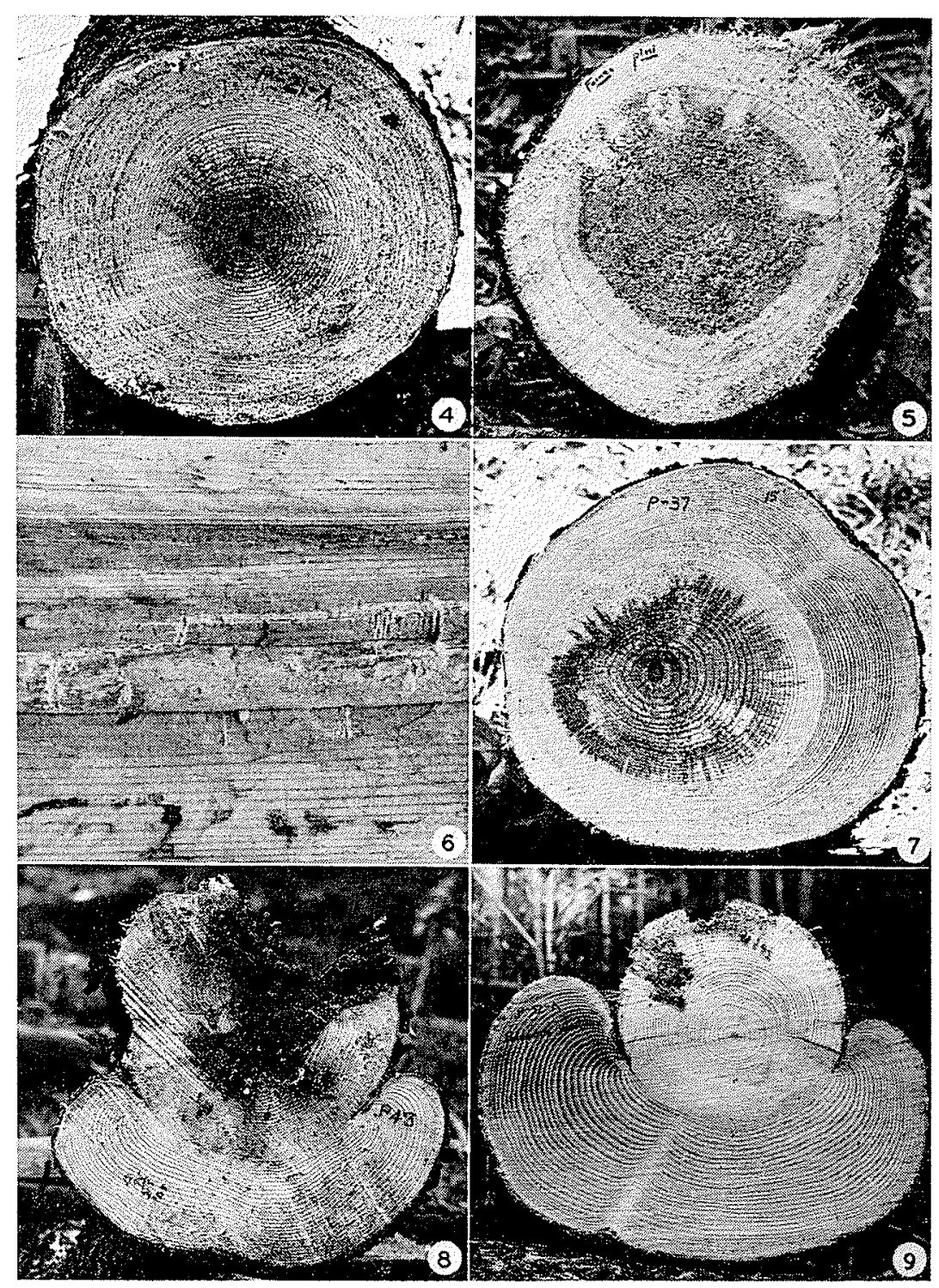

(CAPTIONS NEXT PAGE) 
six inches and sectioned every four feet to a top diameter of three inches inside bark. The precise extent of red stain $^{3}$ and decay in the vicinity of fire scars was determined by sectioning at closer intervals as required and by splitting the bolts. Data such as length of scar, width of scar at 12 inches from ground level, volumes of red stain and decay and sound wood, were recorded on logarithmic paper ${ }^{4}$ designed to facilitate cubic volume computations using a planimeter.

With the exception of Polyporus abietinus Dicks. ex. Fr., which was found occasionally growing on the surface of fire scars, sporophores did not occur on the trees examined. For the identification of the fungi associated with stain or decay it was necessary, therefore, to make cultures on agar for microscopic examination of the mycelium ${ }^{5}$.

TABLE 1

Basic Data on Fire Scars Occurring on Lodgepole Pine Distributed in Three Locations in Alberta

\begin{tabular}{|c|c|c|c|c|c|c|c|c|}
\hline \multirow[b]{2}{*}{ Locality } & \multirow{2}{*}{$\begin{array}{c}\text { Total } \\
\text { no. of } \\
\text { trees }\end{array}$} & \multicolumn{2}{|c|}{$\begin{array}{l}\text { Trees fire- } \\
\text { scarred }\end{array}$} & \multirow{2}{*}{$\begin{array}{l}\text { Av. } \\
\text { age } \\
\text { of } \\
\text { scars }\end{array}$} & \multirow[t]{2}{*}{$\begin{array}{l}\text { Av. } \\
\text { l'gth } \\
\text { of } \\
\text { scars } \\
\text { (feet) }\end{array}$} & \multirow[t]{2}{*}{$\begin{array}{l}\text { Av. } \\
\text { width } \\
\text { of } \\
\text { scars } \\
\text { at 12" } \\
\text { (inches) }\end{array}$} & \multicolumn{2}{|c|}{$\begin{array}{l}\text { Trees with } \\
\text { infections } \\
\text { entering } \\
\text { the fire scar }\end{array}$} \\
\hline & & No. & $\%$ & & & & No. & $\%$ \\
\hline Strachan & 26 & 26 & 100 & 33 & 4.0 & 5.5 & 9 & 35 \\
\hline Strachan & 26 & 22 & 85 & 33 & 3.6 & 5.5 & 9 & 41 \\
\hline Nordegg & 19 & 19 & 100 & 33 & 6.6 & 6.8 & 16 & 84 \\
\hline Nordegg & 25 & 23 & 92 & 33 & 6.8 & 4.3 & 13 & 56 \\
\hline Water Valle & ey 37 & 24 & 65 & 39 & 2.7 & 4.1 & 4 & 17 \\
\hline $\begin{array}{l}\text { Total or } \\
\text { Average }\end{array}$ & 133 & 114 & 86 & 一 & 4.7 & 5.2 & 51 & 45 \\
\hline
\end{tabular}

${ }^{B}$ Red stain is defined as the incipient stage of decay caused by fungi such as Sterentm pini, Stereum sanguinolentutm, Fomes pini, and Polyporus anceps.

"Form SB-239, adapted from United States Department of Agriculture Form 558-A (2).

${ }^{5}$ Appreciation is expressed to Dr. M. K. Nobles and her staff, Botany and Plant Pathology Division, Ottawa, for identifying many of the cultural isolates.

\section{CAPTIONS FOR OPPOSITE PAGE}

FIGURE 4: Red stain caused by Stcreum pini. Note the characteristic rays extending from the central core of light reddish-brown stain.

FIGURE 5: A cross-sectional view of red stain caused by Fomes pini. In general, the stain is a solid core of reddish-brown in contrast to the typical light reddish-brown ray discoloration caused by $S$. pini.

FIGURE 6: A longitudinal section showing red stain caused by Polyporus anceps. In this infection a limited amount of advanced white mycelial development has occurred. FIGURE 7: A cross-sectional view of the reddish-brown ray stain caused by Stereum sanguinolentum.

FIGURE 8: Brown cubical decay caused by Coniophora puteana originating through a basal fire scar.

FIGURE 9: Decay of Polyporus abietinus advancing from the face of a basal fire scar. 


\section{Basic Data}

\section{RESULTS}

Table 1 shows that 114 or $86 \%$ of the trees examined had basal fire scars (Fig. 3). Scar age was uniform at 33 years with the exception at Water Valley where the age of scars was 39 years. The length of scars averaged 4.7 feet and ranged from a low of 2.7 feet at Water Valley to a high of 6.8 feet at Nordegg.

Fifty-one, or $45 \%$, of the trees injured by fire had infections entering the fire scar. This degree of infection varied from $17 \%$ at Water Valley to $84 \%$ at Nordegg (Table I). These differences appeared to be correlated to the length of scar and to the width of scar. For example, at Water Valley the average length of scar was 2.7 feet and the incidence of infected scars, $17 \%$. At Strachan, scars averaged nearly 4.0 feet and the percentage of infection

INDEX OF SCAR AREA

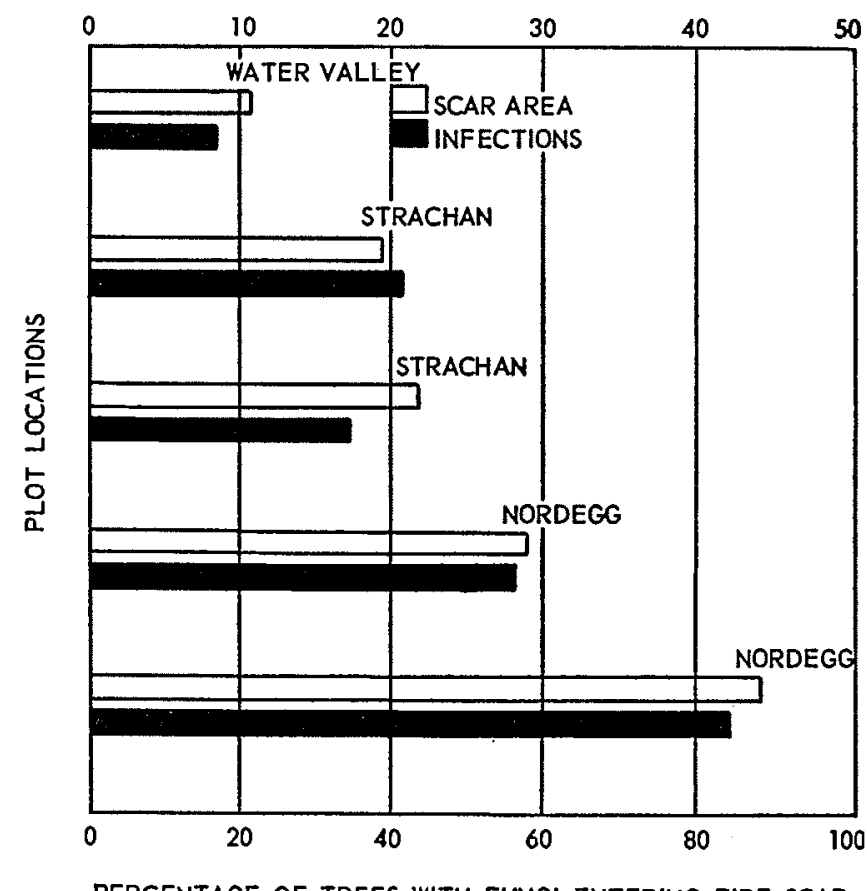

PERCENTAGE OF TREES WITH FUNGI ENTERING FIRE SCAR

FIGURE 2

Scar area index in relation to the percentage of trees with infections originating in basal fire scars. 
was $38 \%$. At Nordegg, scars on one plot averaged 6.6 feet and measured 6.8 inches in width at 12 inches from ground level; $84 \%$ of the scars were infected. The scars on the second plot at Nordegg were comparable in length but the incidence of infection was $56 \%$. However, the average width of scar on this latter plot was only 4.3 inches.

Accordingly, linear regression analyses were made to test the significance of the variables of scar length and scar width and the incidence of fungi entering scars. Scar width is not a significant factor but the regression of incidence of infection on scar length is just barely significant at the 5\% level. When the figures of scar length and scar width are combined to obtain an index of scar area, the result is a regression well over the $1 \%$ level of significance. Scar length, therefore, will give some indication as to the incidence of infections to be expected in a particular stand, but scar width is unreliable. The index of scar area, however, provides the best estimate, the incidence of infection increasing progressively with increasing scar area (Fig. 2).

In the sample of 133 trees $60 \%$ of the infections originated in branch stubs as compared to $21 \%$ in basal fire scars. However, the fire scar infections accounted for $46 \%$ of the stain and decay volume, and the branch stub infections for $39 \%$. This volume of red stain and decay amounted to $4.4 \%$ of the gross merchantable cubic volume of the 51 trees with fire scar infections, or $2.2 \%$ of the gross merchantable cubic volume of the 133 sample trees.

\section{The Fungi Entering Fire Scars}

In the 85-year-old stands examined the percentage of infections through fire scars occurred as follows (Table II): $82 \%$, firm red stain; $12 \%$, white pitted decay; $4 \%$, blue stain; and $2 \%$, brown cubical decay.

TABLE II

The Number and Percentage of Fungus Infections Entering Fire Scars in Lodgepole Pine in Alberta

\begin{tabular}{|c|c|c|c|c|}
\hline \multirow[b]{2}{*}{ Fungus } & \multicolumn{4}{|c|}{ Infections } \\
\hline & & No. & & $\%$ \\
\hline Red Stain & 46 & & 82 & \\
\hline Stereum pini & & 16 & & 27 \\
\hline Polyporus anceps & & 2 & & 4 \\
\hline Stereum sanguinolentum & & 2 & & 4 \\
\hline Fomes pini & & 1 & & 2 \\
\hline Fomes pini and Stereum pini & & 1 & & 2 \\
\hline Non-Basidiomycetes & & 24 & & 43 \\
\hline Brown Cubical Decay & 1 & & 2 & \\
\hline Coniophora puteana & & 1 & & 2 \\
\hline White Pitted Decay & 7 & & 12 & \\
\hline Polyporus abietinus & & 7 & & 12 \\
\hline Blue Stain & 2 & & 4 & \\
\hline Non-Basidiomycetes & & 2 & & 4 \\
\hline TOTALS & & 56 & & 100 \\
\hline
\end{tabular}


Of the fungi associated with red stain, Stereum pini (Schleich. ex Fr.) Fr. (Fig. 4) caused 16 of 21 infections. Other infections of red stain were attributed to Fomes pini (Thore ex Fr.) Karst. (Fig. 5), Polyporus anceps Pk. (Fig. 6), and Stereum sanguinolentum (Alb. \& Schw. ex Fr.) (Fig. 7) (Table II). One infection of brown cubical decay was caused by Coniophora puteana (Schum. ex Fr.) Karst. (Fig. 8), while 12 infections of Polyporus abietinus (Fig. 9) resulted in superficial decay. One of two cases of blue stain was caused by Oidiodendron fuscum Robak.

Infections generally originated at the upper extremity of the visible scar. Where infections originated below the scar apex, adhering bark, possibly providing moisture adequate for spore germination, was prominent on the scar. Other infections started in checks and cracks in the open face of the scar.

\section{Firo Scars and Management Considerations}

Wind-breakage at the butts of fire-scarred trees was of rare and sporadic occurrence and is not considered significant in the management of 85-year-old stands of lodgepole pine in this Province. Mature and overmature trees, however, are subject to an undetermined but apparently higher degree of windbreakage with the subsequent losses of the volumes of entire trees (11).

Approximately 33 years after a ground fire, $46 \%$ of the scarred trees had decay infections in the scars and almost no advanced decay was in evidence. Firm red stain, therefore, is the important defect in the management of the age class studied. The logging of such stands for lumber would involve the degrading in value of measurable volumes of wood. Accordingly, trees with basal fire scars should be cut at the earliest opportunity following a fire.

Assuming that all firm red stain will yield a high recovery of pulp, there appears to be no urgency for reasons of decay to cut fire-scarred trees for pulpwood, at least up to 30 years following a fire. Similarly, the decay cull for poles would be slight according to current regulatory standards (1) which permit firm red stain in this product.

\section{ACKNOWLEDGMENTS}

Grateful acknowledgment is expressed to the following agencies and individuals for various assistance: Alberta Department of Lands and Forests, Forestry Branch, Department of Northern Affairs and National Resources, R. J. Bourchier, D. I. Crossley, W. B. Denyer, D. E. Etheridge, M. K. Nobles, and $\mathrm{C}$. Reimer. 


\section{REFERENCES}

1. Canadian Standards Association. 1948. Specifications for the physical properties and preservation treatment of jack, lodgepole, and red pine poles and reinforcing stubs. Ottawa.

2. CHAPMAN, H. H. and MEYER, W. H. 1949. Forest mensuration. McGraw-Hill Book Company, Inc., New York, Toronto, and London,

3. GUSTAFSON, R. O. 1944. Cull as determined from basal wounds in Kentucky Highlands timber. Jour. Forestry, 42: 181-184.

4. GUSTAFSON, R. O. 1946. Forest fires, basal wounds, and resulting damage to timber in an Eastern Kentucky area. Kentucky Agr. Exper. Station. Bul. 493: 1-15.

5. HEPTING, G. H. 1935. Decay following fire in young Mississippi Delta hardwoods. U.S. Dept. Agr. Tech. Bul. 494: 1-34.

6. HEPTING, G. H. 1941. Prediction of cull following fire in Appalachian oaks. Jour. Agr. Research, 62: 109-120.

7. HEPTING, G. H. and HEDGECOCK, G. G. 1937. Decay in merchantable oak, yellow poplar, and basswood in the Appalachian region. U.S. Dept. Agr. Tech. Bul. 570: 1-30.

8. LACHMUND, H. G. 1923. Bole injury in forest fires. Jour. Forestry, 21: 723-731.

9. McCARTHY, E. F. 1928. Analysis of fire damage in Southern Appalachian Forests. Jour. Forestry, 26: 57-68.

10. NELSON, R. M., SIMS, I. H., and ABELL, M. S. 1933. Basal fire wounds on some Southern Appalachian hardwoods. Jour. Forestry, 31: 829-837.

11. NORDIN, VIDAR J. 1954. Forest pathology in relation to the management of lodgepole pine in Alberta. Forestry Chron. 30: 299-306.

12. TOOLE, E. RICHARD and FURNIVAL, GEORGE M. 1957. Progress of heart rot following fire in bottomland red oaks. Jour. Forestry, 55: 20-24. 